Article

\title{
In Vitro Synergy of Pongamia pinnata Extract in Combination with Antibiotics for Inhibiting and Killing Methicillin-Resistant Staphylococcus aureus
}

\author{
Po-An Su ${ }^{1,2}$, Shun-Lai Li ${ }^{3}$, Hung-Jen Tang ${ }^{1, *}$, Chi-Chung Chen ${ }^{4,5}$, Ying-Chen Lu ${ }^{5}$, \\ Kuo-Chen Cheng ${ }^{1}$, Yi-Chung Lin ${ }^{3}$, Yin-Ching Chuang ${ }^{1,6}$ and Chih-Cheng Lai $7, * \mathbb{C}$ \\ 1 Department of Medicine, Chi Mei Medical Center, Tainan 71004, Taiwan; suboan0421@gmail.com (P.-A.S.); \\ kcg.cheng@gmail.com (K.-C.C.); chuangkenneth@hotmail.com (Y.-C.C.) \\ 2 Department of Pharmacy, Chia Nan University of Pharmacy \& Science, Tainan 71710, Taiwan \\ 3 Department of Biotechnology, Southern Taiwan University of Science and Technology, Tainan 71005, Taiwan; \\ shunlai@mail.stut.edu.tw (S.-L.L.); eg16958@yahoo.com.tw (Y.-C.L.) \\ 4 Department of Medical Research, Chi Mei Medical Center, Tainan 71004, Taiwan; ccomm2@yahoo.com.tw \\ 5 Department of Food Science, National Chiayi University, Chiayi 60004, Taiwan; biolyc2016@gmail.com \\ 6 Departments of Medicine, Chi Mei Medical Center, Liou Ying, Tainan 73657, Taiwan \\ 7 Department of Internal Medicine, Kaohsiung Veterans General Hospital, Tainan Branch, \\ Tainan 71051, Taiwan \\ * Correspondence: 8409d1@mail.chimei.org.tw (H.-J.T.); dtmed141@gmail.com (C.-C.L.)
}

Received: 6 January 2020; Accepted: 28 February 2020; Published: 29 February 2020

\begin{abstract}
Aims: Currently, we face the serious problem of multiple drug-resistant pathogens. The development of new antimicrobial agents is very costly and time-consuming. Therefore, the use of medicinal plants as a source of alternative antibiotics or for enhancing antibiotic effectiveness is important. Methods: The antibacterial effects of aqueous extracts of the seed coat of Pongamia pinnata (Linn.) Pierre in combination with several antibiotics against methicillin-resistant Staphylococcus aureus (MRSA) were tested by broth dilution, checkerboard, and time-kill methods. Results: For the combinations of $P$. pinnata with ampicillin, meropenem, cefazolin, cefotaxime, cefpirome, and cefuroxime, $70 \%$ to $100 \%$ were synergistic, with a fractional inhibitory concentration (FIC) index of $<0.5$. For the time-kill method with $0.5 \times$ minimum inhibitory concentration (MIC) of P. pinnata in combination with $8,4,2$, and $1 \mu \mathrm{g} \mathrm{mL} \mathrm{m}^{-1}$ of the various antibiotics, almost all of the combinations showed synergistic effects, even with the lowest concentrations of P. pinnata, except for aztreonam. No antagonistic effect was observed for these combinations. Conclusions: Based on these findings, aqueous seed coat extracts of $P$. pinnata have good potential for the design of new antimicrobial agents.
\end{abstract}

Keywords: antibiotics; pharmaceuticals; resistance; staphylococcus; antimicrobial

\section{Introduction}

The emergence of multidrug-resistant organisms (MDROs) has become a serious global health concern [1-3]. However, the development of new antibiotics to treat MDROs is both time-consuming and expensive. Therefore, the application of medicinal, plant-based, natural materials with antimicrobial activity provides another solution $[4,5]$. The ethnomedical plant Pongamia pinnata (Linn.) Pierre, which belongs to the family Leguminosae, is a glabrous, fast-growing tree in coastal and limestone areas of southern Taiwan and other tropical Asian countries [6,7]. Different parts of the P. pinnata tree have been widely used in making remedies for various types of infection [8-10] or inflammatory illnesses such as bronchitis and rheumatoid arthritis [11,12]. Based on the findings of previous studies [8-12], we studied the antimicrobial properties of P. pinnata against several gram-positive and gram-negative 
bacteria. In this preliminary investigation, we found that clinical isolates of pathogenic bacteria, including some MDROs, were susceptible to aqueous extracts of the seed coat of P. pinnata using the agar dilution method. Moreover, this aqueous extract exerted low minimum inhibitory concentrations (MICs) against Staphylococcus spp. (ranging from 0.39 to $0.78 \mathrm{mg} \mathrm{mL}^{-1}$ ). Therefore, this study was conducted to evaluate the synergistic effects of $P$. pinnata extract combined with other antibiotics against methicillin-resistant Staphylococcus aureus (MRSA).

\section{Materials and Methods}

\subsection{Bacterial Strains}

Ten MRSA isolates from clinical specimens, including blood, joint fluid, and other aseptic specimens, were randomly obtained from the clinical microbiology laboratory of the Chi-Mei Medical Center. Staphylococcal species were identified based on colony morphology, Gram stain morphology, and coagulase test results and further confirmed by VITEK II methods. MRSA was stored at $-70{ }^{\circ} \mathrm{C}$ in Protect Bacterial Preservers (Technical Service Consultants Limited, Heywood, Lancashire, England) before use.

\subsection{Pulsed-field Gel Electrophoresis}

PFGE was performed on Staphylococcus aureus DNA. In brief, bacterial chromosomal DNA was digested by using SmaI (New England Biolabs, Beverly, MA, USA). Electrophoresis was carried out for $22 \mathrm{~h}$ at $14{ }^{\circ} \mathrm{C}$ with pulse times ranging from 2 to $40 \mathrm{~s}$ at $6 \mathrm{~V} \mathrm{~cm}^{-1}$ using the Bio-Rad CHEF MAPPER apparatus (Bio-Rad Laboratories, Richmond, CA, USA). A dendrogram based on an unweighted pair grouping was generated by previously described methods [13]. Isolates that had $>80 \%$ similarity of their PFGE profiles were considered closely related strains according to the Dice correlation coefficient and the unweighted pair-group method, with averages within a position tolerance of $0.8 \%$ and an optimization parameter of 1\% [14,15]. All ten MRSA isolates were confirmed as genetically unrelated based on the PFGE patterns (Figure 1).
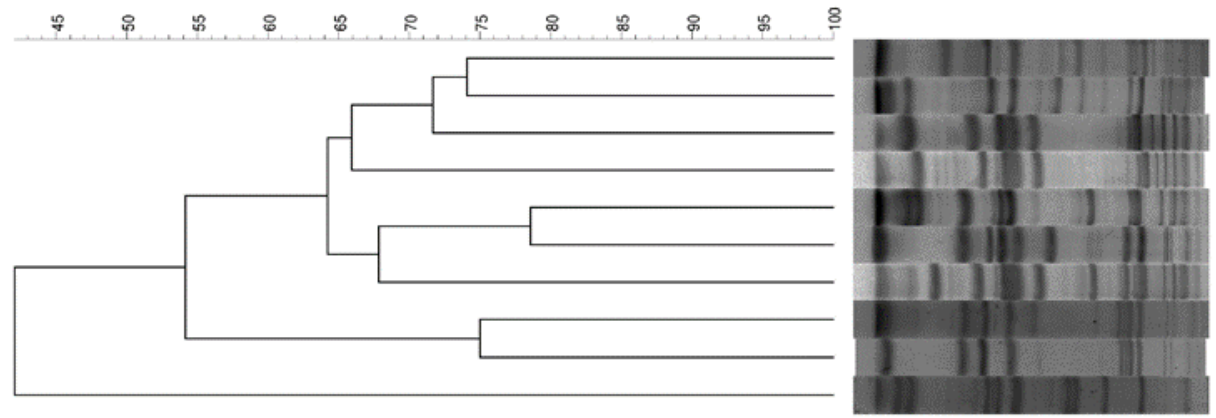

MRSA 252

MRSA 3562

MRSA 3337

MRSA 3315

MRSA 3322

MRSA 3509

MRSA 3641

MRSA 3626

MRSA 3643

MRSA 3635

Figure 1. Pulsed-field gel electrophoresis patterns of all methicillin-resistant Staphylococcus aureus (MRSA) isolates.

\subsection{Preparation of Aqueous Seed Coat Extracts}

P. pinnata seeds were collected from dried fruits and surface-sterilized in $70 \%$ ethyl alcohol, and the seed coat was collected. Aqueous extracts were prepared by soaking the seed coat powder in $50{ }^{\circ} \mathrm{C}$ hot water for $24 \mathrm{hr}$ and then evaporating it to dryness.

\subsection{Minimum Inhibitory Concentration (MIC) and Minimum Bactericidal Concentration (MBC) of P. pinnata Extract}

The broth microdilution assay was used to determine the MIC and MBC. The crude extract was dissolved in type 1 ultrapure water at a concentration of $50 \mathrm{mg} \mathrm{mL}^{-1}$ and then diluted with Mueller-Hinton broth (Oxoid, Basingstoke, UK) to $6.25 \mathrm{mg} \mathrm{mL}^{-1}$. The inhibition of bacterial growth 
was defined as a clear well. The lowest concentration showing no turbidity change was considered the MIC. For determination of the $\mathrm{MBC}, 10 \mu \mathrm{L}$ of liquid from each well was dropped onto Mueller-Hinton Agar and incubated at $37^{\circ} \mathrm{C}$ for $24 \mathrm{~h}$. The lowest concentration that showed no growth was taken as the MBC. Experiments were performed in triplicate and repeated twice.

\subsection{Antibiotics}

The antibiotics tested were ampicillin, cefazolin, cefuroxime, cefotaxime, and aztreonam (Sigma Chemical Co.), cefpirome (Hoechst), and meropenem (ICI Pharmaceuticals). MICs were determined by broth microdilution. Interpretation criteria for susceptibility testing were based on the Clinical and Laboratory Standards Institute guidelines [16-18]. The inoculum concentration was $5 \times 10^{5}$ colony forming units (CFU) $\mathrm{mL}^{-1}$. The inoculated trays and plates were incubated in ambient air at $37^{\circ} \mathrm{C}$ for 18-24 hr. The MIC was defined as the lowest antibiotic concentration that yielded no visible growth after overnight incubation. S. aureus American Type Culture Collection 29213 was included in each run as the standard quality control strain.

\subsection{Time-kill Studies}

MRSA 3322 was randomly selected. The time-kill method was performed according to the Clinical and Laboratory Standards Institute methodology [18]. In brief, bacterial suspensions were diluted to approximately $5 \times 10^{5} \mathrm{CFU} \mathrm{mL} \mathrm{m}^{-1}$ in $25 \mathrm{~mL}$ of fresh Mueller-Hinton broth. In the time-kill study with $P$. pinnata only, 4-, 2-, 1-, and 0.5-fold MICs were tested, and bacterial numbers were determined at 0, 2, 4, $6,8,12$, and 24 hours.

In the P. pinnata extract plus antibiotic combination time-kill studies, $0.39 \mathrm{mg} \mathrm{mL}^{-1} P$. pinnata extract (0.5-fold MIC) was used as a reagent control. P. pinnata extract at $0.39 \mathrm{mg} \mathrm{mL}^{-1}$ plus $8,4,2$, and $1 \mu \mathrm{g} \mathrm{mL} \mathrm{m}^{-1}$ of each antibiotic was tested to determine the combined effects.

Bacterial counts were measured at 0,8 , and $24 \mathrm{~h}$ by counting the colonies in 10 -fold serially diluted $100 \mathrm{~mL}$ aliquots plated on nutrient agar (Difco Laboratories, Sparks, MD) and were incubated at $37^{\circ} \mathrm{C}$. Synergy was defined as a $\geq 2 \log 10$ decrease in CFU mL ${ }^{-1}$ between the combination and its most active constituent after $24 \mathrm{~h}$, with the number of surviving organisms in the presence of the combination $\geq 2 \log 10$ CFU mL ${ }^{-1}$ less than the starting inoculum. Bacteriostatic and bactericidal activities were defined as $3 \log 10$ and $\geq 3 \log 10$ reductions in CFU mL ${ }^{-1}$ relative to that of the starting inoculum, respectively, at $24 \mathrm{~h}$. All experiments were performed twice.

\subsection{Checkerboard Microdilution Assay}

The initial concentration of each bacterial suspension was $1.5 \times 10^{5} \mathrm{CFU} \mathrm{mL}^{-1}$. The final drug concentrations ranges were $6.25-0.098 \mathrm{mg} \mathrm{mL}^{-1}$ for $P$. pinnata, 256-0.25 $\mu \mathrm{g} \mathrm{mL} \mathrm{m}^{-1}$ for ampicillin, cefazolin, cefuroxime, cefotaxime, cefpirome, and aztreonam, and $32-0.25 \mu \mathrm{g} \mathrm{mL}^{-1}$ for meropenem. Two-fold dilutions of each drug or drug combination were tested. The results were read after plates were incubated at $37^{\circ} \mathrm{C}$ for 24 hours. The following formulas were used to calculate the fractional inhibitory concentration (FIC) index: FIC of drug A = MIC of drug A in combination/MIC of drug A alone; FIC of drug B = MIC of drug B in combination/MIC of drug B alone; and FIC index = FIC of drug A + FIC of drug B. Synergy was defined as an FIC index of $\leq 0.5$, indifference as an FIC index of $>0.5$ but $\leq 4$, and antagonism as an FIC index of $>4$ [19].

\section{Results}

Table 1 provides the MIC and MBC values for the 10 MRSA isolates. The ratio of the MBC/MIC for the $P$. pinnata extract against the 10 MRSA isolates were all $\leq 4$. 
Table 1. The ratio of minimal bactericidal concentration/minimal inhibitory concentration (MBC/MIC) of Pongamia pinnata extract against 10 methicillin-resistant Staphylococcus aureus (MRSA) isolates.

\begin{tabular}{cccc}
\hline Isolates. & MBC $\left(\mathbf{m g} \mathbf{~ m L}^{-\mathbf{1}}\right)$ & $\mathbf{M I C}\left(\mathbf{m g} \mathbf{~ m L}^{-\mathbf{1}}\right)$ & $\mathbf{M B C} \mathbf{M I C}$ \\
\hline MRSA 252 & 0.78 & 0.78 & 1 \\
MRSA 3315 & 1.56 & 0.39 & 4 \\
MRSA 3322 & 1.56 & 0.78 & 2 \\
MRSA 3337 & 1.56 & 0.39 & 4 \\
MRSA 3509 & 1.56 & 0.39 & 4 \\
MRSA 3562 & 1.56 & 0.39 & 4 \\
MRSA 3626 & 0.78 & 0.78 & 1 \\
MRSA 3635 & 3.12 & 0.78 & 2 \\
MRSA 3641 & 1.56 & 0.78 & 2 \\
MRSA 3643 & 1.56 & 0.39 & 4 \\
\hline
\end{tabular}

Table 2 shows the checkerboard microdilution results for each of the seven antimicrobial agents in combination with the P. pinnata seed coat extract against the 10 MRSA isolates. For the combinations of P. pinnata with ampicillin, meropenem and cefazolin, 10 out of 10 isolates were synergistic, with an FIC index $\leq 0.5$. For the combination of P. pinnata with cefotaxime and cefpirome, 9 out of 10 isolates were synergistic; 7 out of 10 isolates were synergistic for the cefuroxime combination. Only the combination of P. pinnata extract with aztreonam had no synergistic effect, and the FIC index was 0.5 to 4 . None of the combinations showed antagonism.

Table 2. The checkerboard microdilution assay of seven antimicrobial agents combined with a crude extract of Pongamia pinnata seed coat against 10 methicillin-resistant Staphylococcus aureus isolates. The initial concentration of each bacterial suspension was $1.5 \times 10^{5} \mathrm{CFU} \mathrm{mg} \mathrm{mL}^{-1}$. The final drug concentration ranged from $6.25-0.098 \mathrm{mg} \mathrm{mL}^{-1}$ for the extract and $256-0.25 \mu \mathrm{g} \mathrm{mL}^{-1}$ for the antibiotics.

\begin{tabular}{cccccccc}
\hline \multirow{2}{*}{ Class } & \multirow{2}{*}{ Antibiotic } & \multicolumn{3}{c}{ FIC Index } & \multirow{2}{*}{ Range } & Mean & \multirow{2}{*}{ SD } \\
\cline { 3 - 5 } & & $\mathbf{7}$ & $\mathbf{7} \mathbf{0 . 5}, \mathbf{4}$ & $\leq \mathbf{0 . 5}$ & & & \\
\hline Penicillins & Ampicillin & 0 & 0 & 10 & $0.25-0.5$ & 0.43 & 0.1 \\
Carbapenems & Meropenem & 0 & 0 & 10 & $0.25-0.5$ & 0.36 & 0.09 \\
Cephalosporins & Cefazolin & 0 & 0 & 10 & $0.266-0.375$ & 0.33 & 0.04 \\
& Cefuroxime & 0 & 3 & 7 & $0.266-0.504$ & 0.4 & 0.1 \\
& Cefotaxime & 0 & 1 & 9 & $0.188-0.516$ & 0.33 & 0.11 \\
& Cefpirome & 0 & 1 & 9 & $0.281-0.563$ & 0.46 & 0.09 \\
Monobactams & Aztreonam & 0 & 10 & 0 & $0.75-1$ & 0.98 & 0.08 \\
\hline
\end{tabular}

The suspensions of randomly selected isolates of MRSA 3322 were cocultivated with $0.5,1,2$, and $4 \times$ the concentration of the respective MICs of the aqueous extracts for the time-kill assay. The inhibition effect persisted for 48 hours under the effect of $2 \times$ and $4 \times$ MIC (Figure 2). 


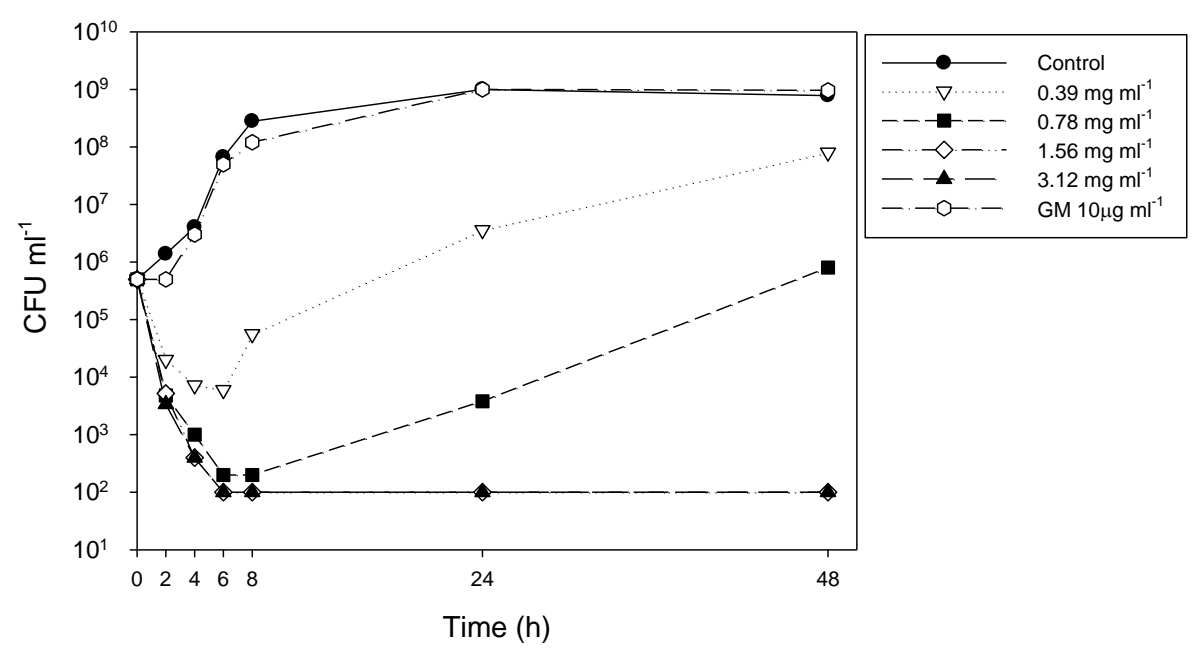

Figure 2. Time-kill results for the crude extract of Pongamia pinnata seed coat alone against methicillin-resistant Staphylococcus aureus 3322 incubated for $48 \mathrm{hr}$. The concentrations used were $0.5 \times$, $1 \times, 2 \times$, and $4 \times$ minimum inhibitory concentration, with an inoculum concentration of $5 \times 10^{5}$ colony forming units (CFU) $\mathrm{mL}^{-1}$. Note. GM, gentamicin.

When MRSA 3322 was co-cultivated with $0.5 \times$ MIC of P. pinnata and $1 \times$ MIC $\left(32 \mu \mathrm{g} \mathrm{mL}^{-1}\right)$ of ampicillin, the inhibitory effect persisted for only 8 hours, and then regrowth occurred (Figure $3 \mathrm{~A}$ ). When co-cultivated with $0.5 \times$ MIC of $P$. pinnata extract and $1 \mu \mathrm{g} \mathrm{mL}^{-1}$ ampicillin, the inhibitory effect persisted for 8 hours, and then regrowth occurred. When cocultivated with $0.5 \times$ MIC of P. pinnata extract and 8,4 , and $2 \mu \mathrm{g} \mathrm{mL} \mathrm{m}^{-1}$ ampicillin, the inhibitory effect persisted for 24 hours. When MRSA 3322 was co-cultivated with $0.5 \times$ MIC of $P$. pinnata extract and $1 \times \mathrm{MIC}\left(64 \mu \mathrm{g} \mathrm{mL}{ }^{-1}\right)$ of cefazolin, the inhibitory effect persisted for only 8 hours, and regrowth occurred (Figure 3B). When co-cultivated with $05 \times$ MIC of $P$. pinnata extract and $8,4,2$, and $1 \mu \mathrm{g} \mathrm{mL}{ }^{-1}$ cefazolin, the inhibitory effect persisted 24 hours before regrowth.

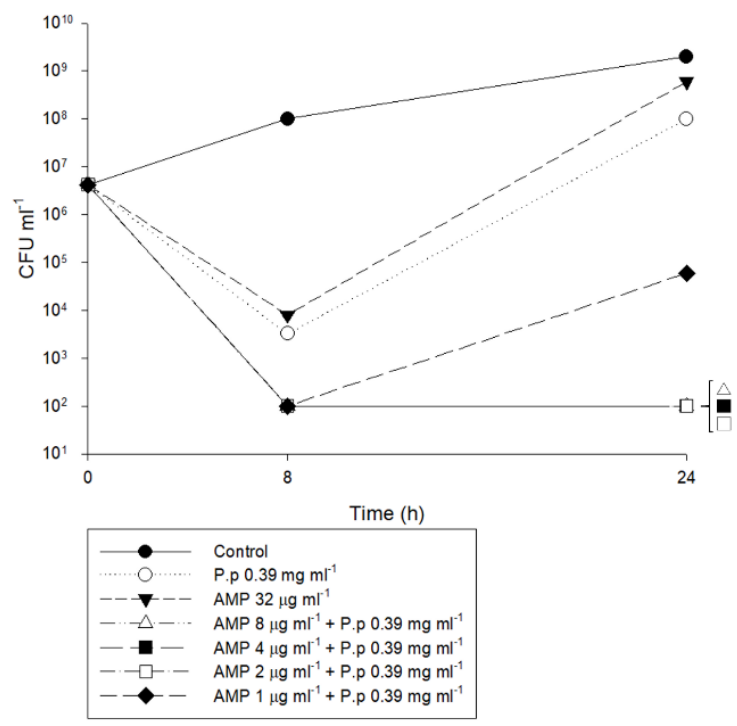

(A) 


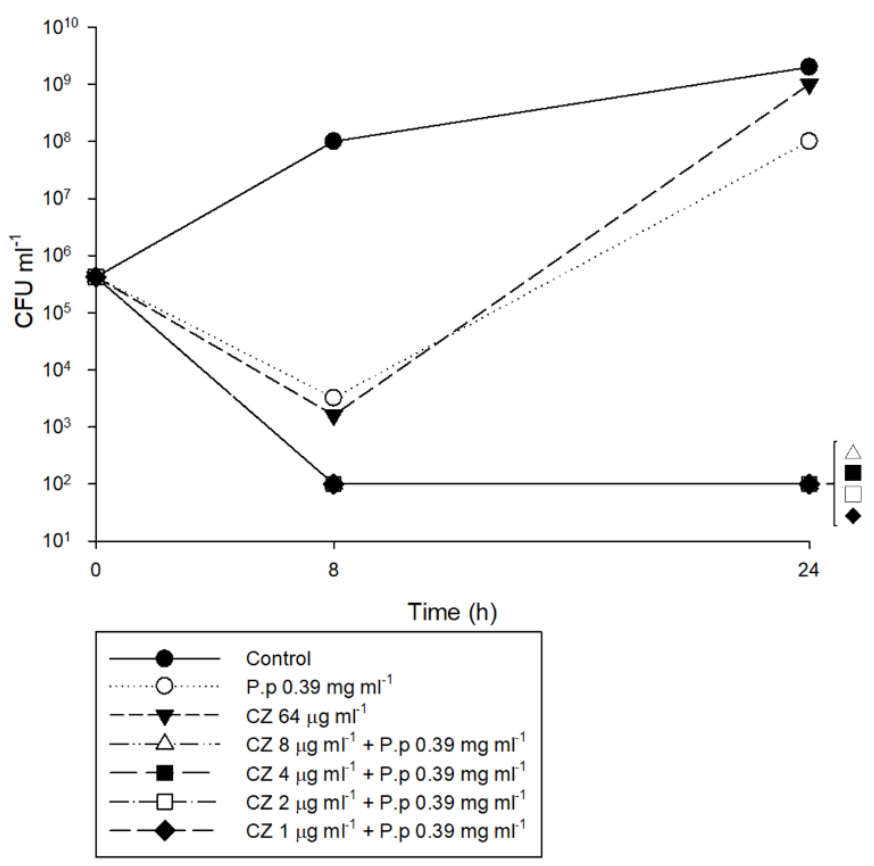

(B)

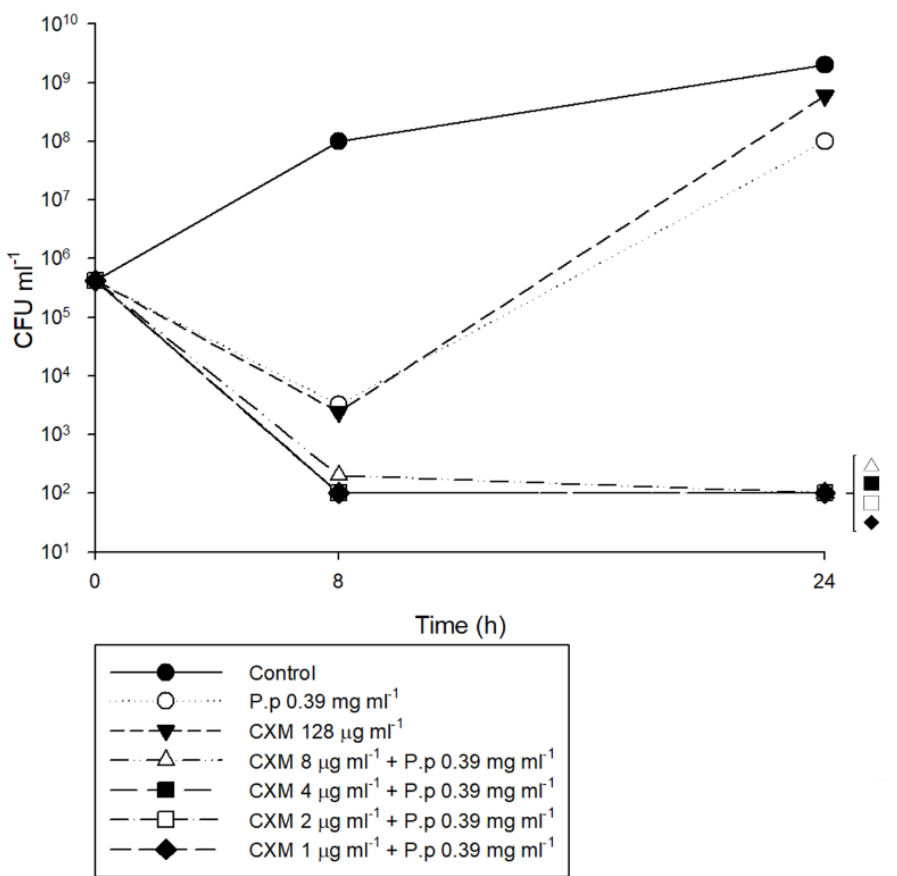

(C) 


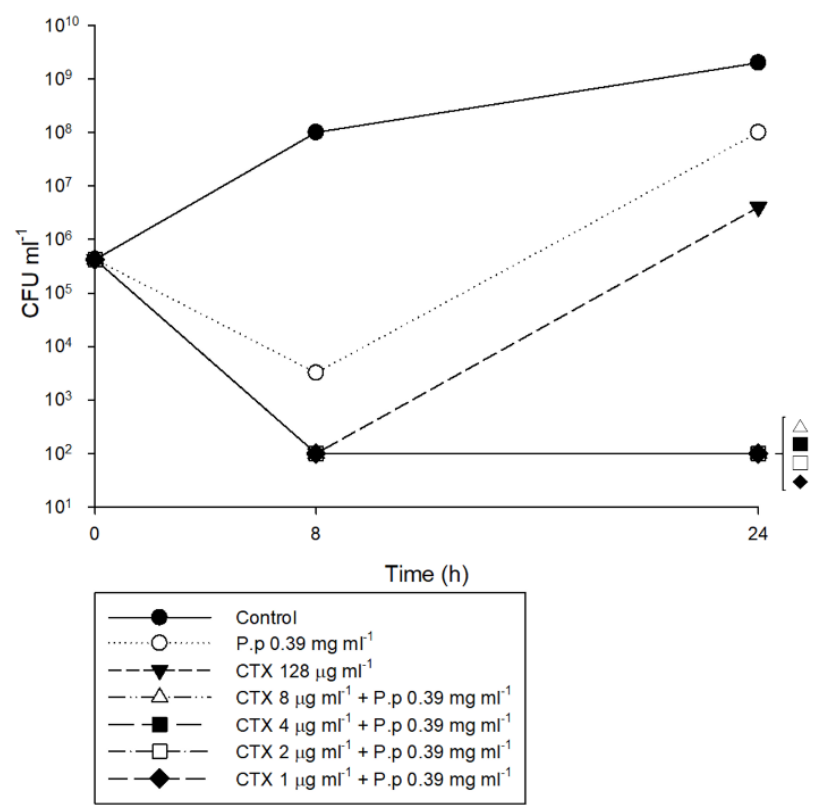

(D)

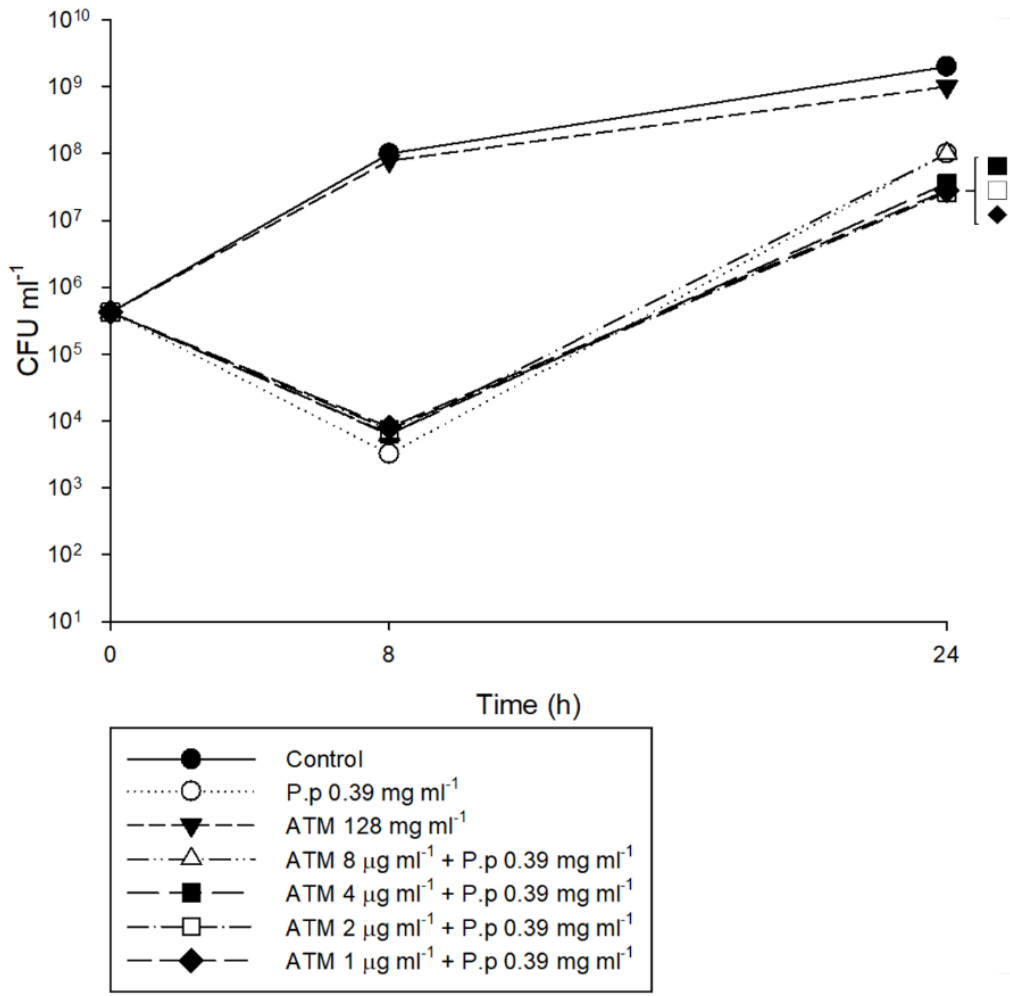

(E) 


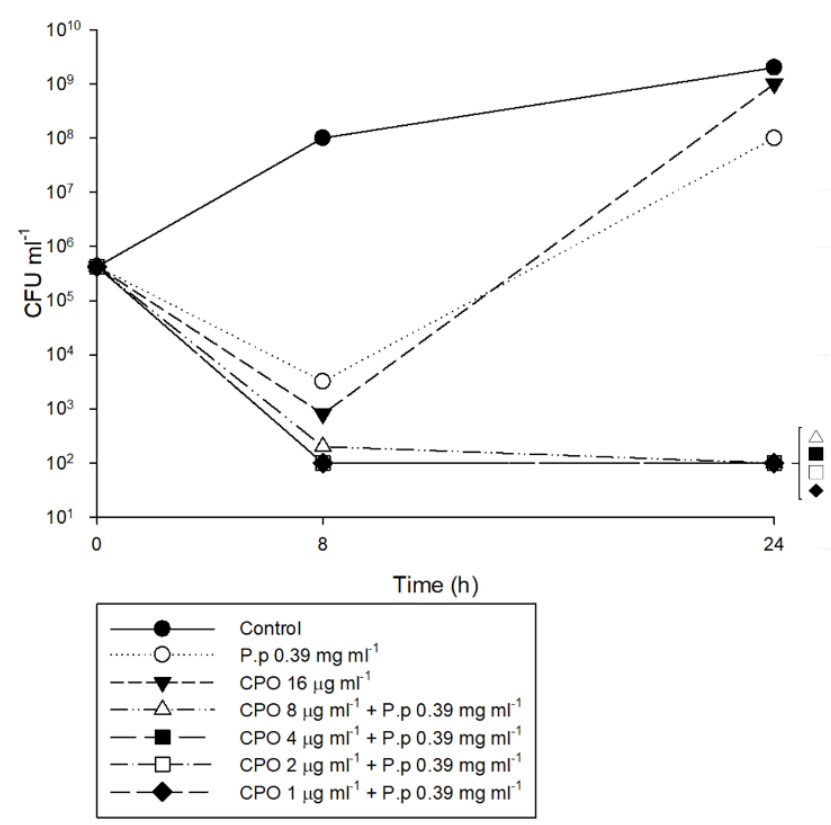

(F)

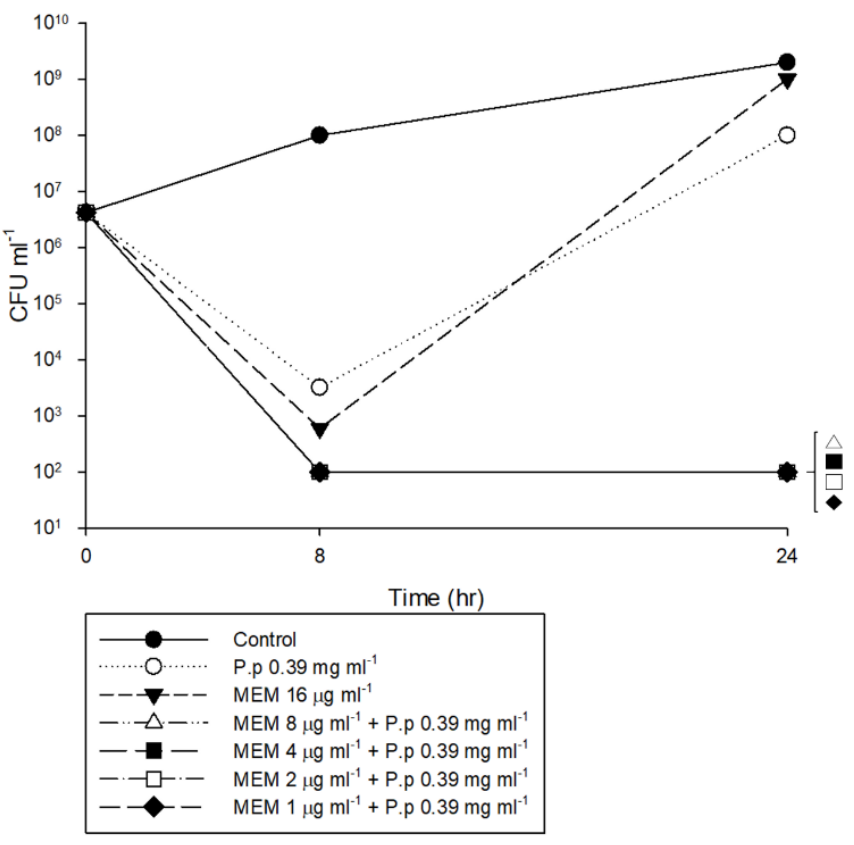

(G)

Figure 3. Time-kill results for the crude extract of Pongamia pinnata seed coat (concentration: $0.5 \times$ minimum inhibitory concentration, MIC) in combination with seven antibiotics including (A): ampicillin (AMP), (B): cefazolin (CZ), (C): cefuroxime (CXM), (D): cefotaxime (CTX), (E): aztreonam (ATM), (F): cefpirome (CPO), and (G): meropenem (MEM) against methicillin-resistant Staphylococcus aureus 3322 incubated for $48 \mathrm{hr}$. The concentration used was $1 \times \mathrm{MIC}$, and 8, 4, 2, and $1 \mu \mathrm{g} \mathrm{mL}^{-1}$ of each of the different antibiotics were evaluated. The inoculum concentration was $5 \times 10^{5}$ colony forming units (CFU) $\mathrm{mL}^{-1}$. 
When MRSA 3322 was co-cultivated with $1 \times$ MIC of cefuroxime, cefotaxime $\left(128 \mu \mathrm{g} \mathrm{mL}^{-1}\right)$, and cefpirome $\left(16 \mu \mathrm{g} \mathrm{mL} \mathrm{m}^{-1}\right)$, the inhibitory effect persisted for only 8 hours, and regrowth occurred (Figure 3C,D,F). When co-cultivated with $0.5 \times$ MIC of $P$. pinnata extract and 8, 4, 2, and $1 \mu \mathrm{g} \mathrm{mL}-1$ cefuroxime, cefotaxime, and cefpirome, the inhibitory effect persisted 24 hours before regrowth occurred. When MRSA 3322 was co-cultivated with $1 \times$ MIC of meropenem $\left(16 \mu \mathrm{gL}^{-1}\right)$, the inhibitory effect persisted for only 8 hours, and then regrowth occurred (Figure 3G). When co-cultivated with $0.5 \times$ MIC of $P$. pinnata extract and 8, 4, 2, and $1 \mu \mathrm{g} \mathrm{mL}^{-1}$ meropenem, the inhibitory effect persisted 24 hours before regrowth occurred. When MRSA 3322 was co-cultivated with $1 \times$ MIC $\left(128 \mu \mathrm{g} \mathrm{mL}^{-1}\right)$ of aztreonam alone or co-cultivated with $0.5 \times$ MIC of $P$. pinnata combined with $8,4,2,1 \mu \mathrm{g} \mathrm{mL} \mathrm{m}^{-1}$ aztreonam, the inhibitory effects of all treatments persisted for only 8 hours before regrowth occurred (Figure 2E). All antibiotics except aztreonam had synergistic effects when combined with P. pinnata extract, even at low concentrations.

\section{Discussion}

Herbal medicine is one of the most important fields of traditional medicine in the world [20]. Previous studies have reported on the benefits of $P$. pinnata extracts including the gastro-protective properties of seed extracts in adult male albino rats, the anti-hyperglycemic and anti-lipid peroxidative activities of fruit extracts in diabetic rats, and the antimicrobial activity of bark, seed, and leaf extracts against various bacteria and fungi [21-24]. In this study, we investigated the in vitro activity of a combination of $P$. pinnata seed coat extract with various antibiotics against MRSA. We found that the crude aqueous extracts of the seed coat of $P$. pinnata resulted in MBC/MIC ratios of $<4$. The time-kill assays revealed bactericidal effects at $2 \times$ and $4 \times$ MIC for the antibiotics tested. These findings indicated that the P. pinnata extract has bactericidal effects on MRSA but that high concentrations are required for it to be effective when used alone. On the other hand, when the extract was combined with various antibiotics that were typically not inhibitory to MRSA, we observed synergistic effects between the P. pinnata extract and most of the tested antibiotics, even at very low concentrations, except for aztreonam. A previous study found that the combination of vancomycin and $\beta$-lactam antibiotics is synergistic against staphylococci with reduced susceptibilities to vancomycin [25]. Most $\beta$-lactam antibiotics used alone have no killing effect on MRSA. However, when they are used with an anti-MRSA agent, they enhance its killing effect [26]. Such a mechanism and result may explain our experimental finding of synergy between P. pinnata extract and the $\beta$-lactam antibiotics tested, which showed enhanced killing of MRSA.

In this study, we did not study the possible active antibacterial component of $P$. pinnata extract. However, previous studies have investigated this issue. Various extracts of the plant exhibited antibacterial activity against a broad spectrum of bacteria. The plant possesses numerous phytoconstituents such as flavones, flavans, chalcone, triterpenes and aromatic carboxylic acids, which are possibly responsible for the antibacterial activity [26,27]. In addition, the toxicity of the extracts of $P$. pinnata has been evaluated in animal studies $[28,29]$. In acute toxicity studies, rats treated with crude seed extracts of $P$. pinnata at a dose of $2000 \mathrm{mg} / \mathrm{kg}$ body weight were safe at 14 observation days [28]. In subacute toxicity studies, the rats were treated orally with $P$. pinnata crude seed extract suspensions at a dose of $1600 \mathrm{mg} / \mathrm{kg}$ body weight daily for 20 days, and the test drug did not produce significant toxic effects except mild to moderate pathological changes observed in the spleen and liver [29]. Overall, these findings suggest that $P$. pinnata is relatively safe.

A literature search for studies of $P$. pinnata extracts revealed no other scientific investigations regarding the antimicrobial effects of aqueous seed coat extracts inhibiting antibiotic-resistant bacteria, particularly MRSA. We restricted our study to the aqueous seed coat extract since the antimicrobial activity could be attributed to the synergistic effects of the combination of various components present in the aqueous extract. Further study including chromatography is necessary to clarify the chemical and pharmacological properties of the extract. Based on these results, we suggest that P. pinnata has promising antimicrobial activity and synergistic effects with other antibiotics used for the treatment 
of MRSA. Such plant extracts may be used to develop new pharmaceuticals of natural origin for antimicrobial purposes.

Our study has some limitations. First, the relatively high values of $P$. pinnata MICs in our experiments could be attributed to the crude extracts and unknown active constituents. Second, a greater number of bacterial species need to be tested to confirm the activity of the extract.

In conclusion, water extracts of $P$. pinnata seed coat have excellent in vitro synergistic inhibitory effects in combination with several antibiotics used against MRSA. The combinations exhibited synergistic in vitro MRSA killing effects. The aqueous extract of the seed coat of $P$. pinnata has potential as an antimicrobial agent for clinical use, especially for the treatment of MRSA.

Author Contributions: Conceptualization, P.-A.S., S.-L.L., H.-J.T., K.-C.C., Y.-C.C. and C.-C.L.; Data curation, H.-J.T. and Y.-C.L. (Ying-Chen Lu); Formal analysis, H.-J.T.; Investigation, S.-L.L., C.-C.C., Y.-C.L. (Ying-Chen Lu), K.-C.C., Y.-C.L. (Yi-Chung Lin) and Y.-C.C.; Writing - original draft, P.-A.S.; Writing - review \& editing, C.-C.L. and H.-J.T. All authors have read and agreed to the published version of the manuscript.

Funding: This research received no external funding.

Acknowledgments: The authors thank the members of the Research Laboratory of Infectious Diseases of the Chi-Mei Medical Center for their assistance.

Conflicts of Interest: The authors declare no conflict of interest.

\section{References}

1. Oteo, J.; Miró, E.; Pérez-Vázquez, M.; Navarro, F. Evolution of carbapenemase-producing Enterobacteriaceae at the global and national level: What should be expected in the future? Enferm. Infecc. Microbiol. Clin. 2014, 4, 17-23. [CrossRef]

2. Ling, L.L.; Schneider, T.; Peoples, A.J.; Spoering, A.L.; Engels, I.; Conlon, B.P. A new antibiotic kills pathogen without detectable resistance. Nature 2015, 517, 455-459. [CrossRef] [PubMed]

3. Arias, C.A.; Murray, B.E. A new antibiotic and the evolution of resistance. N. Engl. J. Med. 2015, 372, 1168-1170. [CrossRef] [PubMed]

4. Liu, Q.; Yao, H. Antioxidant activities of barley seeds extracts. Food Chem. 2007, 102, 732-737. [CrossRef]

5. Iqbal, S.; Bhanger, M.I.; Anwar, F. Antioxidant properties and components of bran extracts from selected wheat varieties commercially available in Pakistan. LWT_Food Sci. Technol. 2007, 40, 361-367. [CrossRef]

6. Jigna, P.; Rathish, N.; Sumitra, C. Preliminary screening of some folklore medicinal plants from western India for potential antimicrobial activity. Indian J. Pharmacol. 2005, 37, 408.

7. Parmar, B.; Sahrawat, K.; Mukerjee, S. Pongamia glabra: Constituents \& uses. J. Sci. Ind. Res. 1976, 35, 608-6011.

8. Li, L.; Li, X.; Shi, C.; Deng, Z.; Fu, H.; Proksch, P. Pongamone A-E, five flavonoids from the stems of a mangrove plant, Pongamia pinnata. Phytochemistry 2006, 67, 1347-1352. [CrossRef]

9. Tanaka, T.; Ilnuma, M.; Yuki, K.; Fujii, Y.; Mizuno, M. Two new $\beta$-hydroxychalcones from the root bark of Pongamia pinnata. Chem. Pharm. Bull. 1991, 39, 1473-1475. [CrossRef]

10. Kitagawa, I.; Zhang, R.; Hori, K.; Tsuchiya, K.; Shibuya, H. Indonesian medicinal plants. II. Chemical structures of Pongapinones A and B, two new phenylpropanoids from the bark of Pongamia pinnata (Papilionaceae). Chem. Pharm. Bull. (Tokyo) 1992, 40, 2041-2043. [CrossRef]

11. Mamatha, B. Screening of medicinal plants used in rural Indian folk medicine for treatment of diarrhoea. Pharmaceutical Reviews. 2006. Available online: http://www.pharmainfo.net/e-journal (accessed on 12 April 2019).

12. Carcache-Blanco, E.J.; Kang, Y.-H.; Park, E.J.; Su, B.-N.; Kardono, L.B.; Riswan, S. Constituents of the stem bark of Pongamia pinnata with the potential to induce quinone reductase. J. Nat. Prod. 2003, 66, 1197-1202. [CrossRef] [PubMed]

13. Garcia-Garrote, F.; Cercenado, E.; Marin, M.; Bal, M.; Trincado, P.; Corredoira, J. Methicillin-resistant Staphylococcus aureus carrying the mecC gene: Emergence in Spain and report of a fatal case of bacteraemia. J. Antimicrob. Chemother. 2014, 69, 45-50. [CrossRef] 
14. Cookson, B.D.; Robinson, D.A.; Monk, A.B.; Murchan, S.; Deplano, A.; De Ryck, R. Evaluation of molecular typing methods in characterizing a European collection of epidemic methicillin-resistant Staphylococcus aureus strains: The HARMONY collection. J. Clin. Microbiol. 2007, 45, 1830-1837. [CrossRef]

15. Bosch, T.; de Neeling, A.J.; Schouls, L.M.; van der Zwaluw, K.W.; Kluytmans, J.A.; Grundmann, H. PFGE diversity within the methicillin-resistant Staphylococcus aureus clonal lineage ST398. BMC Microbiol. 2010, 10, 40. [CrossRef]

16. Clinical and Laboratory Standards Institute. Methods for Dilution Antimicrobial Susceptibility Tests for Bacteria that Grow Aerobically —18th Edition Approved Standard M07-A7; CLSI: Wayne, PA, USA, 2006.

17. Clinical and Laboratory Standards Institute. Performance Standards for Antimicrobial Susceptibility Testing; 16th Informational Supplement. Document M100-S16; CLSI: Wayne, PA, USA, 2006.

18. National Committee for Clinical Laboratory Standards. Methods for Determining Bactericidal Activity of Antimicrobial Agents; Approved Guideline. Document M26-A; NCCLS: Wayne, PA, USA, 1999.

19. White, R.L.; Burgess, D.S.; Manduru, M.; Bosso, J.A. Comparison of three different in vitro methods of detecting synergy: Time-kill, checkerboard, and E test. Antimicrob. Agents Chemother. 1996, 40, 1914-1918. [CrossRef] [PubMed]

20. Chopra, R.N.; Nayer, S.; Chopra, I. Glossary of Indian Medicinal Plants, 3rd ed.; Council of Scientific \& Industrial Research: New Delhi, India, 1992.

21. Punitha, R.; Manoharan, S. Antihyperglycemic and antilipidperoxidative effects of Pongamia pinnata (Linn.) Pierre flowers in alloxan induced diabetic rats. J. Ethnopharmacol. 2006, 105, 39-46. [CrossRef] [PubMed]

22. Shabir, G.; Anwar, F.; Sultana, B.; Khalid, Z.M.; Afzal, M.; Khan, Q.M. Antioxidant and antimicrobial attributes and phenolics of different solvent extracts from leaves, flowers and bark of Gold Mohar [Delonix regia (Bojer ex Hook.) Raf]. Molecules 2011, 16, 7302-7319. [CrossRef]

23. Babu, D.R.; Rao, G.N. In vitro studies on extracts of Pongamia pinnata (L.) Pierre flowers as a potent antioxidant. Int. J. Agric. Food Sci. Technol. 2010, 1, 7-11.

24. Sajid, Z.I.; Anwar, F.; Shabir, G.; Rasul, G.; Alkharfy, K.M.; Gilani, A.H. Antioxidant, antimicrobial properties and phenolics of different solvent extracts from bark, leaves and seeds of Pongamia pinnata (L.) Pierre. Molecules 2012, 17, 3917-3932. [CrossRef]

25. Climo, M.W.; Patron, R.L.; Archer, G.L. Combinations of vancomycin and beta-lactams are synergistic against staphylococci with reduced susceptibilities to vancomycin. Antimicrob. Agents Chemother. 1999, 43, 1747-1753. [CrossRef]

26. Sowjanya, P.; Srinivasa Babu, P.; Neelima Lakshmi, D.; Navyasri, Y.; Harshini, J. A phyto pharmacological review on a versatile medicinal plant: Pongamia pinnata (L.) pierre. J. Pharmacogn. Phytochem. 2018, 7, 459-463.

27. Gargade, V.A.; Kadam, D.G. In vitro evaluation of antibacterial potential of Pongamia pinnata L. against Xanthomonas axonopodis punicae, phytopathovar of bacterial blight of Pomegranate (Punica granatum). Int. J. Curr. Microbiol. App. Sci. 2015, 4, 824-833.

28. Aneela, S.; De, S.; Lakshmi, K.K.; Choudhury, N.; Das, B.L.; Vidya Sagar, K. Acute oral toxicity studies of Pongamia pinnata and Annona squamosa on Albino Wister rats. Int. J. Res. Pharm. Chem. 2011, 1, 820-824.

29. Chandni, G.; Ashwani, U. Oral toxicity study of Karanja seed churana (Pongamia pinnata pierre) on Albino rats. Int J. Adv. Res. 2017, 5, 159-168. [CrossRef]

(C) 2020 by the authors. Licensee MDPI, Basel, Switzerland. This article is an open access article distributed under the terms and conditions of the Creative Commons Attribution (CC BY) license (http://creativecommons.org/licenses/by/4.0/). 